\title{
Relative Iron "Overload" in Offspring of Patients with Type 2 Diabetes Mellitus: A New Component in the Conundrum of Insulin Resistance Syndrome?
}

\author{
Agathoklis Psyrogiannis ${ }^{1}$, Venetsana Kyriazopoulou ${ }^{1}$, Argiris Symeonidis ${ }^{2}$, \\ Michalis Leotsinidis ${ }^{3}$, Apostolos G. Vagenakis \\ ${ }^{1}$ Department of Medicine, Division of Endocrinology and Diabetes, ${ }^{2}$ Division of Hematology, ${ }^{3}$ Department of Public \\ Health, University of Patras Medical School, Patras, Greece
}

\begin{abstract}
There are a few reports suggesting that subtle disturbances of iron metabolism are frequently found in patients with type 2 diabetes (DM2), but it is not known if these disturbances precede or accompany the diabetic state. We investigated the serum iron indices in 41 offspring of DM2 parents (group I) with normal glucose tolerance, and in 49 offspring whose parents had no history of DM2 and were matched for sex, age, body mass index (BMI), waist to hip ratio (WHR) and blood pressure (group II). Serum iron, ferritin, total iron binding capacity (TIBC), transferrin saturation, serum triglycerides, cholesterol, Apo-B, high density lipoprotein (HDL) and glucose and insulin values during an oral glucose tolerance test were measured. Insulin resistance was assessed using the homeostasis model assessment (HOMA - Insuline resistence index-IRI). In comparison to controls (group II), the offspring of DM2 subjects (group I) had higher fasting serum triglycerides (mean \pm SD $2.25 \pm 2.08$ vs. $1.6 \pm 0.8 \mathrm{mmol} / \mathrm{L}, \mathrm{p}<0,05)$, lower HDL cholesterol $(0.96 \pm 0.2$ vs. $1.1 \pm$ $0.2 \mathrm{mmol} / \mathrm{L}, \mathrm{p}<0.001)$, higher total cholesterol $(5.5 \pm 1.1 \mathrm{vs} .5 .1 \pm 0.8 \mathrm{mmol} / \mathrm{L}, \mathrm{p}<0.05)$, higher apo-B-lipoprotein $(133.2 \pm 34.3$ vs. $125.5 \pm 30.5 \mathrm{mg} / \mathrm{dl}, \mathrm{p}<0.05)$, higher LDL-C $(3.7 \pm 0.8$ vs. $3.2 \pm$ $0.6 \mathrm{mmol} / \mathrm{L})$, higher $\gamma$-GT $(28 \pm 10$ vs. $17 \pm 5.6 \mathrm{IU} / \mathrm{L}, \mathrm{p}<0.01)$ higher insulin in the Area Under the Curve $(204.7 \pm 140.8$ v. $153.1 \pm 63.0 \mu \mathrm{U} / \mathrm{ml}, \mathrm{p}<0.05)$ and higher HOMA-IRI $(2.84 \pm 1.39$ vs. $1.67 \pm 0.77$, $\mathrm{p}<0.001)$, higher serum ferritin concentrations $(98.3 \pm 57.7 \mathrm{vs} .62 .0 \pm 41.1 \mathrm{ng} / \mathrm{ml}, \mathrm{p}<0.01)$, higher serum iron concentration $(20.2 \pm 6.0 \mu \mathrm{mol} / \mathrm{L}$ vs. $14.5 \pm 4.3, \mathrm{p}<0.001)$ and higher transferrin saturation index $(31.3 \pm 8.4$ vs. $22.6 \pm 7.3, p<0.0001)$. By single linear analysis in the offspring of DM2 parents, there was a positive correlation of IRI with transferrin saturation $(r=0.400, p<0.01)$, fibrinogen $(r=0.377, p=0.025)$ and ferritin concentration $(r=0.344, p=0.041)$, and a negative correlation with $\operatorname{TIBC}(r=-0.477, p<0.0001)$, while stepwise multiple regression analysis, IRI showed a positive correlation with fibrinogen $(b=0.64, t=3.746, p<0.001)$, triglycerides $(b=0.37, t=2.619$, $p<0.01)$ and ferritin $(b=0.20, t=1.827, p=0.05)$. No correlation of IRI, with any of the above parameters was seen in the offspring of normal parents. By logistic regression analysis the parameters characterizing the offspring of parents with DM2 were IRI (OR 14.9 CI 2.4-91.0) serum iron (OR 44.2 CI 6.9-281), TIBC (OR 6.1 CI 1.01-37.0 and $\gamma$-GT (OR 29.6 CI 5.0-174). In conclusion, the data indicate that the iron load, is significantly increased in offspring of DM2 subjects with unaffected glucose tolerance. Furthermore, ferritin concentration is related to insulin resistance. Hence, the relative iron "overload" in offspring of type 2 diabetics is present along with insulin resistance and might worsen the hepatic insulin insensitivity already present in these patients.
\end{abstract}

Key words: iron overload, insulin resistance, diabetes mellitus, ferritin, TIBC

Address correspondence and requests for reprints to:

Apostolos G. Vagenakis, M.D., Professor and Chairman, Department of Internal Medicine, University of Patras, Medical School, Patras, Greece 26 500, Tel./Fax: +302610 993982, email:vag.inmd@med.upatras.gr

Received 23-01-03, Revised 26-04-03, Accepted 24-06-03 


\section{INTRODUCTION}

Abnormalities in the regulation of peroxide production, free radicals transition, metal metabolism and oxidative stress have been postulated as playing a role in the pathogenesis and late complications of diabetes mellitus $(\mathrm{DM})^{1-5}$. Oxygen free radicals promote the oxidation of lipids, rendering them suitable to penetrate the endothelial wall and therefore to become more atherogenic ${ }^{6}$. Free iron catalyzes free radical production which generates oxidants that can induce lipid oxidation ${ }^{1-9}$.

It is reasonable to hypothesize that disturbances of iron metabolism may be related to insulin resistance, a condition known to predispose to atherosclerosis. Moreover, it is well known that the incidence of $\mathrm{DM}$ is very high in hemochromatosis and that insulin resistance is also present in patients with $\beta$-thalassemia with high serum ferritin levels ${ }^{10-12}$. Serum ferritin has been reported to be increased in patients with diabetes mellitus type 2(DM2) and type $1^{10}$. It is not known whether this is due to abnormal glycosylation and therefore to increased half life of ferritin, or is simply an accompanying disturbance not related to insulin resistance. Recently, an association of serum ferritin values and insulin resistance has been reported in apparently healthy individuals, but these subjects were not matched for sex, body mass index (BMI) and age, and no parental history of DM2 was recorded ${ }^{13}$. In another study, serum ferritin levels have been proposed as representing a cardiovascular risk factor ${ }^{14}$.

We therefore undertook a study to examine whether normal offspring of parents with DM2 and normal glucose tolerance display any differences in serum iron concentration, total iron binding capacity (TIBC), ferritin and transferrin saturation in comparison to offspring whose parents had no history of type 1 or 2 DM, and whether the Insulin Resistance Index (IRI) is related to these parameters in these individuals. Such a study, to our knowledge, has not been previously reported.

\section{SUBJECTS AND METHODS}

We studied 54 healthy offspring of 54 unrelated families (group I). The subjects were Caucasians, of Greek origin and had one parent who developed DM2 after the age of 50 years. Two individuals had both parents with DM2. Maturity-onset diabetes of the young was excluded on the basis of the late onset of diabetes. 54 subjects with no family history for diabetes (group II), matched for sex, age, BMI and waistto-hip ratio (WHR), served as controls. All subjects had a normal physical examination with no history of gastrointestinal bleeding, hepatitis or menstrual disturbances. Of the female subjects, $3 / 13$ in group I and $5 / 18$ in group II were menstruating. They also had normal values for routine laboratory parameters including hematology, fibrinogen, $\mathrm{C}$-reactive protein, $\mathrm{HbA1c}$ (upper limit of normal 6.5\%), adrenal, kidney, liver and thyroid function. The subjects were not under any medication known to affect carbohydrate, lipoprotein or iron metabolism and all denied alcohol intake and nutrition supplements containing iron. After an appropriate carbohydrate diet for one week, an oral Glucose Tolerance Test (OGTT) was performed and patients with impaired glucose tolerance or type 2 diabetes were excluded from the study. Fortyone subjects remained in group I and 49 in group II.

\section{Study design}

After a 12-h overnight fast, blood samples were drawn for serum glucose, insulin, lipids, lipoprotein and ferritin, iron and TIBC.

Serum ferritin was measured by radioimmunoassay. Iron level and TIBC were determined by routine laboratory tests. Transferrin saturation was calculated as the quotient of serum iron by the simultaneously measured TIBC. The intake of natural nutrients, including dietary iron, was estimated using the Nutrica Computer program for calculation of nutrient intake ${ }^{15}$.

The subjects ingested $75 \mathrm{~g}$ of glucose over a 2-min period. Blood samples were drawn at 30,60 and 120 min thereafter for measurement of serum glucose and insulin concentrations. Plasma glucose was measured with an automatic analyzer applying the glucose oxidase method. Insulin was determined by radioimmunoassay (RIA) kit. Insulin resistance was calculated using the homeostasis model assessment (HOMAIRI) $)^{16-18}$.

The areas under the glucose and insulin curves (AUC) during the OGTT were calculated using the formula: $0.25 \mathrm{x}$ (fasting value) $+0.5 \mathrm{x}(1 / 2 \mathrm{~h}$ value $)+$ $0,75 \mathrm{x}(1 \mathrm{~h}$ value $)+0.5 \mathrm{x}(2 \mathrm{~h}-\text { value })^{19}$.

The study design was approved by the ethical and 
scientific committee of the Hospital and informed consent was obtained from all subjects participating in the study.

\section{STATISTICAL ANALYSIS}

Results are expressed as mean along with standard deviation. Data were analyzed by using the SPSS version 11.0 statistical package (SPSS Inc. USA). Unpaired Student's t-test was applied to compare the parameters between the two groups. Pearson correlation coefficient was used to assess the relation between the various parameters. Multivariate analysis of variance was applied to evaluate the glucose tolerance and the insulin response between the groups. A stepwise multiple regression analysis was used to ascertain the independent predictive value of each studied parameter on IRI. To estimate odds ratios, forward stepwise logistic regression was applied after dichotomization of the independent parameters in the median, setting the group as dependent variable. The statistical inferences were based on the level of significance $\mathrm{p}<0.05$.

\section{RESULTS}

The clinical characteristics of the study population are shown in Table 1 . The group of offspring with type 2 diabetic parents as well as the control group had a similar distribution of age, sex, BMI, WHR, systolic and diastolic blood pressure (BP). Serum lipids and iron concentrations and the related parameters are presented in Tables 1 and 2. No difference in the hematocrit, hemoglobin, $\mathrm{MCV}$ and $\mathrm{MCH}$ values between the two groups were observed. The mean fasting serum triglycerides, apo-B, total cholesterol and LDLcholesterol were higher and serum HDL lower in group I compared to the control group. Serum fibrinogen was measured only in Group I patients.

Serum ferritin concentration was higher in group I compared to group II $(98.3 \pm 57.5$ vs. $62.0 \pm 41.2 \mathrm{ng} /$ $\mathrm{ml}, \mathrm{p}<0.01)$, as well as serum iron concentration $(20.2 \pm 6.0$ vs. $14.5 \pm 4.5 \mu \mathrm{mol} / \mathrm{L} \mathrm{p}<0.001)$ (Table 2). The TIBC was comparable in both groups $(64.1 \pm 10.4$ vs. $65 \pm 9.6 \mu \mathrm{mol} / \mathrm{L})$. The transferrin saturation was higher in group I compared to group II $(31.3 \pm 8.4$ vs. $22.6 \pm 7.3 \mathrm{p}<0.0001$, Table 2).

Table 1. Clinical characteristics and laboratory values of the offspring of type 2 diabetes parents (group I) and offspring of normal parents (group II)

\begin{tabular}{|c|c|c|c|c|c|}
\hline & \multirow{2}{*}{$\begin{array}{c}\text { Group I } \\
\text { mean }\end{array}$} & \multicolumn{3}{|c|}{ Group II } & \multirow[t]{2}{*}{ P value } \\
\hline & & s.d. ${ }^{*}$ & mean & s.d.* & \\
\hline $\mathrm{n}(\mathrm{M} / \mathrm{F})$ & $41(28 / 13)$ & & $49(31 / 18)$ & & NS \\
\hline Age (yr) & 41.4 & 6.8 & 43.4 & 5.5 & NS \\
\hline $\mathrm{BMI}\left(\mathrm{kg} / \mathrm{m}^{2}\right)$ & 28.1 & 4.8 & 27.6 & 3.5 & NS \\
\hline WHR & 0.87 & 0.10 & 0.80 & 0.08 & NS \\
\hline Systolic BP (mmHg) & 119.4 & 15.5 & 120.8 & 10.8 & NS \\
\hline Diastolic BP (mmHg) & 72.1 & 12.8 & 73.9 & 10.1 & NS \\
\hline Hematocrit (\%) & 42.5 & 2.9 & 42.1 & 3.1 & NS \\
\hline Hemoglobin (g/dl) & 13.87 & 0.92 & 13.78 & 1.01 & NS \\
\hline $\operatorname{MCV}(\mathrm{fl})$ & 88.1 & 2.5 & 88.5 & 2.9 & NS \\
\hline $\mathrm{MCH}(\mathrm{pg})$ & 29.1 & 1.3 & 29.5 & 1.6 & NS \\
\hline Triglycerides (mmol/l) & 2.25 & 2.08 & 1.60 & 10.80 & $<0.05$ \\
\hline Cholesterol (mmol/l) & 5.5 & 1.1 & 5.1 & 0.8 & $<0.05$ \\
\hline HDL-cholesterol (mmol/l) & 0.96 & 0.20 & 1.10 & 0.20 & $<0.001$ \\
\hline LDL-cholesterol (mmol/l) & 3.7 & 0.8 & 3.2 & 0.6 & $<0.05$ \\
\hline Apo-B lipoprotein (mg/dl) & 133.2 & 34.3 & 125.5 & 30.5 & $<0.05$ \\
\hline Fibrinogen (mg/dl) & 314 & 71 & Not Done & - & - \\
\hline$\gamma-\mathrm{GT}(\mathrm{U} / \mathrm{l})$ & 28.0 & 10 & 17.2 & 5.6 & $<0.05$ \\
\hline
\end{tabular}

s.d.* std deviation 
Table 2. Serum iron indices of the studied subjects (mean \pm SD)

\begin{tabular}{lccccc}
\hline & $\begin{array}{c}\text { Group I } \\
\text { mean }\end{array}$ & s.d. ${ }^{*}$ & $\begin{array}{c}\text { Group II } \\
\text { mean }\end{array}$ & s.d.* & P value \\
\hline $\mathrm{n}$ & 41 & & 49 & & \\
Ferritin $(\mathrm{ng} / \mathrm{ml})$ & 98.3 & 57.7 & 62.0 & 41.2 & $<0.01$ \\
Iron $(\mu \mathrm{mol} / \mathrm{l})$ & 20.2 & 6.0 & 14.5 & 4.3 & $<0.01$ \\
TIBC $(\mu \mathrm{mol} / \mathrm{l})$ & 64.0 & 10.4 & 65.0 & 9.6 & $\mathrm{NS}$ \\
Transferrin Saturation & & & & & \\
Index (Iron x 100/TIBC) & 31.3 & 8.4 & 22.6 & 7.3 & $<0.01$ \\
\hline
\end{tabular}

The glucose and insulin concentrations, in the fasting state (O time) and after an oral glucose challenge, are shown in Table 3 . The mean glucose concentration was significantly higher in group I compared to group II only in the fasting state ( $4.5 \pm 0.6$ vs. $4.3 \pm 0.6$ $\mathrm{mmol} / \mathrm{L}, \mathrm{p}<0.05)$, whereas the between subjects differences were not significant. Moreover, the area under the glucose curve was comparable in the two groups. Serum insulin concentration was higher in group I than in group II at zero time sample, $(14.0 \pm 6.4$ vs. $8.6 \pm 3.2 \mu \mathrm{U} / \mathrm{ml}), 30 \mathrm{~min}(122.2 \pm 94.3$ vs $81.7 \pm 50.6$ $\mu \mathrm{U} / \mathrm{ml})$ and $60 \mathrm{~min}(134.4 \pm 103.1$ vs. $99.9 \pm 48.9 \mu \mathrm{U} /$ $\mathrm{ml} \mathrm{p}<0.05)$. The results from testing the between sub- jects effect group indicate that this effect is significant at $\alpha=0.05(p=0.026)$. The area under the insulin curve was higher in group I ( $205 \pm 141$ vs. $153 \pm 63 \mu \mathrm{U} /$ $\mathrm{ml}, \mathrm{p}<0.05)$, than in group II. HOMA-IRI was significantly higher in group I compared to group II $(2.84 \pm 1.39$ vs. $1.67 \pm 0.77, \mathrm{p}<0.001)$.

In the offspring of the diabetic parents, the insulin resistance index was positively correlated at a statistically significant level with serum fibrinogen $(r=0.38$, $\mathrm{p}=0.025)$, triglycerides $(\mathrm{r}=0.31, \mathrm{p}=0.045), \operatorname{LDL}(\mathrm{r}=$ $0.38, \mathrm{p}=0.031)$, transferrin saturation $(\mathrm{r}=0.41, \mathrm{p}=$ $0.008)$, and negatively with TIBC $(\mathrm{r}=-0.47, \mathrm{p}<0.001)$. Insulin Resistance Index and AUC of insulin were also positively correlated with serum ferritin values $(\mathrm{r}=$ $0.34, p=0.03$, and $r=0.33, p=0.04$, respectively). There was no correlation of IRI with any of the above parameters in the control group, although serum fibrinogen was not measured in this group. Using a stepwise multiple regression model with Insulin Resistance Index as independent variable, the remaining factors were: triglycerides $(b=0.22, t=2.27, p=0.03)$, ferritin $(b=0.06, t=2.29, p=0.02)$, LDL $(b=1.04, t=$ 4.06, $\mathrm{p}<0.001)$, cholesterol $(\mathrm{b}=-0.84 \mathrm{t}=-3.53 \mathrm{p}=$ $0.036)$ and $\operatorname{TIBC}(b=-0.04, t=-3.35, p<0.001)$. The

Table 3. Serum insulin, glucose, glucose and insulin under the curve and insulin resistance index in offspring of DM2 parents (group I) and control subjects (group II) during an oral glucose challenge (mean \pm SD)

\begin{tabular}{|c|c|c|c|c|c|}
\hline & \multicolumn{2}{|c|}{ Group I } & \multicolumn{2}{|c|}{ Group II } & \multirow[t]{2}{*}{ P value (Anova) } \\
\hline & mean & s.d.* & mean & s.d.* & \\
\hline Number (n) & 41 & & 49 & & \\
\hline \multicolumn{6}{|l|}{ Glucose (mmol/l) } \\
\hline Fasting & 4.53 & 0.62 & 4.26 & 0.56 & \\
\hline $30 \mathrm{~min}$ & 8.4 & 2.0 & 8.3 & 1.5 & NS \\
\hline $60 \mathrm{~min}$ & 8.4 & 3.0 & 8.9 & 2.5 & \\
\hline $120 \mathrm{~min}$ & 5.4 & 1.3 & 5.6 & 5.6 & \\
\hline AUC glucose $(\mathrm{mmol} / \mathrm{l})$ & 14.4 & 3.7 & 14.6 & 2.8 & NS \\
\hline \multicolumn{6}{|l|}{ Insulin $(\mu \mathrm{U} / \mathrm{ml})$} \\
\hline Fasting & 14.0 & 6.4 & 8.6 & 3.2 & \\
\hline & $(5-36)$ & $(3-17)$ & & & \\
\hline $30 \mathrm{~min}$ & 122.2 & 94.3 & 81.7 & 50.6 & $p=0.026$ \\
\hline $60 \mathrm{~min}$ & 134.4 & 103.1 & 99.9 & 48.9 & \\
\hline $120 \mathrm{~min}$ & 76.9 & 81.0 & 70.5 & 40.7 & \\
\hline AUC insulin $(\mu \mathrm{U} / \mathrm{ml})$ & 205 & 141 & 153 & 63 & $<0.05$ \\
\hline HOMA-IRI & 2.84 & 1.39 & 1.67 & 0.77 & $<0.001$ \\
\hline
\end{tabular}

AUC: area under the curve

HOMA IRI: Insulin resistance index. Homeostasis model assessment of insulin resistance ${ }^{16-18}$ 
results of multiple regression analysis are shown in Table 4.

To estimate the odds ratios of the parameters referred to in Tables 1 and 2, logistic regression analysis was applied using the group as independent variable. Table 5 presents the parameters gained statistical significance along with corresponding odds ratio and $95 \%$ confidence intervals.

\section{DISCUSSION}

Resistance to insulin-stimulated glucose uptake is a characteristic finding in patients with $\mathrm{DM} 2^{20}$. The observation that concordance for type-2 diabetes approaches $100 \%$ when one identical twin has the disease strongly suggests that the decisive component of this syndrome is genetic in nature ${ }^{21}$. Several studies have shown that offspring of at least one parent with DM2 display hyperinsulinism and are more resistant to insulin action than offspring of parents whose glucose tolerance was normal ${ }^{22-25}$.

The results of our study support and expand these findings. We found that offspring of patients with DM2, when compared with normal individuals whose parents had no history of DM2 and were matched for sex, age and BMI, had higher insulin values, higher fasting serum triglycerides, lower HDL cholesterol,

Table 4. Results of Multiple Regression Analysis, Using as Dependent Variable the IRI.

\begin{tabular}{lcccc}
\hline & \multicolumn{4}{c}{ ALL PATIENTS } \\
Independent variable & $\mathbf{b}$ & $\mathbf{S E}_{\mathbf{b}}$ & $\mathbf{t}$ & $\mathbf{p}$ \\
\hline Triglycerides & 0.22 & 0.09 & 2.27 & 0.02 \\
Ferritin & 0.06 & 0.03 & 2.39 & 0.02 \\
TIBC & -0.03 & 0.01 & -3.35 & $<0.01$ \\
Cholesterol & -0.84 & 0.23 & -3.52 & $<0.01$ \\
Group & 0.73 & 0.21 & 3.44 & $<0.01$ \\
\hline
\end{tabular}

Table 5. Remaining factors in logistic multivariate stepwise analysis Independent variable.: Group

\begin{tabular}{lcc}
\hline Parameter & OR & 95\% CI \\
\hline IRI & 14.88 & $2.44-90.87$ \\
Fe & 44.18 & $6.93-281.47$ \\
TIBC & 6.12 & $1.01-37.29$ \\
$\gamma$-GT & 29.66 & $5.05-174.20$ \\
\hline
\end{tabular}

$\mathrm{OR}=$ Odds Ratio, $\mathrm{CI}=$ Confidence Intervals higher apo-B lipoprotein and higher insulin resistance index, assessed by HOMA. Moreover, the serum iron concentration, serum ferritin and transferrin saturation were found to be substantially higher in offspring of parents with DM2 compared to offspring of normal parents.

We also found a strong negative correlation of insulin resistance index with TIBC and a strong positive correlation with transferrin saturation and serum ferritin. The fact that correlation of insulin resistance index with serum iron levels was not seen does not attenuate the significance of our findings. It is well known that the levels of serum iron are influenced by many factors, such as acute phase proteins, inflammatory cytokines and, therefore, serum iron is not considered the best parameter expressing the iron-status. Instead, transferrin saturation is affected much less by the above-mentioned factors and is used as a more reliable parameter indicating the iron status. To our knowledge, this is the first study which clearly demonstrates that almost all parameters of iron metabolism are set up at higher levels in apparently normal individuals with positive family history of diabetes with an underlyling decreased insulin sensitivity, compared to controls.

Our study differs from previously reported studies $^{13,26-31}$ in certain aspects. First, the offspring group from parents with DM2 was carefully matched to healthy individuals as far as medical history, age, sex, BMI and WHR are concerned. Second, the individuals with impaired glucose tolerance were excluded from both groups. Third, as far as the iron indices are concerned, we included, besides serum ferritin and serum iron levels, the TIBC and the transferrin saturation index. The latter better reflects the iron transport since only the iron not found in hemoglobin, myoglobin and the transport protein transferrin is bound to ferritin?

The cause of increased serum iron, ferritin and transferrin saturation index in offspring of parents with DM2 is not readily apparent. It has been reported that these parameters accompany the insulin resistance state since ferritin in particular is increased in patients with DM2 and in some patients with type 1 diabetes ${ }^{10,11}$. In our study, as judged by multiple regression analysis, the levels of serum ferritin were related to Insulin Resistance Index, which is in concordance with the latter findings. It appears, therefore, that the dis- 
turbances in iron metabolism observed in the present study may be the result of insulin resistance in the liver since they are found in offspring of parents with DM2 without evidence of frank or incipient glucose intolerance. The disturbances in iron metabolism accompany all other metabolic parameters known to characterize the insulin resistance syndrome such as increased triglycerides, lower HDL, higher serum insulin levels, also found in our offspring of DM2 parents. This is strengthened by the finding that the higher values of the parameters of iron metabolism found in the offspring of parents with type 2 diabetes were strongly correlated with insulin resistance index, whereas no correlation was found in the offspring of normal individuals.

A tentative hypothesis about the contribution of iron status in the pathogenesis of the insulin resistance syndrome can be formulated. It is possible that, to some degree, the liver of patients with higher iron stores might become even more "insensitive" to insulin as judged by the higher serum insulin levels and the higher insulin resistance index in the offspring of type 2 diabetic parents. Non-cirrhotic patients with hemochromatosis are hyperinsulinemic and have normal glucose tolerance ${ }^{32}$. Recently it has been reported that $22 \%$ of patients with DM2 had at least one copy of the C282 Y hemochromatosis gene, suggesting that subtle iron metabolism abnormalities, similar to those found in our study, might be found in these patients $^{33,34}$.

There are also other data to support the proposed hypothesis. Wannamethee et $\mathrm{al}^{35}$ recently reported that there is a linear association between hematocrit level and the risk of DM2 over a 12-year follow-up period. Catalano et al have found that the glucose clearance rate was inversely related to hematocrit ${ }^{36}$. High serum hemoglobin values have been associated with subsequent glucose intolerance and DM2 ${ }^{37,38}$. Increased levels of ferritin were found in several patients with type 2 diabetes ${ }^{11,39,40}$. In the Third National Health and Nutrition Examination Survey, increased risk of newly diagnosed diabetes was observed among participants with transferrin saturations less than $45 \%{ }^{41}$. Derangement in other serum parameters of iron metabolism are frequently found in patients with poorly controlled diabetes mellitus and short term control in glucose values is associated with marked decrease in serum ferritin levels ${ }^{39}$. Other studies, however, do not sup- port the iron "overload" as a contributing factor in the development of DM2. Liver iron stores measured in liver biopsy speciments are not increased in patients with type 2 diabetes $^{42}$. Desferioxamine therapy had no effect on glucose homeostasis in patients with DM2 and elevated serum ferritin levels ${ }^{43}$.

Another possible explanation for the increased transferrin and iron as well as the increased transferrin saturation index in the offspring of type 2 diabetic patients may be an early, still silent, non-alcoholic steatohepatitis (NASH) resulting from hyperinsuline$\mathrm{mia}^{44,45}$. This is strengthened by the fact that $\gamma$-GT, an early sign of NASH, was increased in the offspring of parents with DM2 and was positively correlated with insulin resistance. Most of our patients were hyperinsulinemic and, therefore, it is reasonable to postulate that the fat concentration per gram of liver tissue would be increased. This may lead to local IL- 6 and TNF $\alpha$ production ${ }^{46}$ resulting in mild chronic inflammation, which may explain the increase in ferritin decreased transferring, and concequent increased transferrin saturation index. It must be pointed out, however, that in our patients the increased transferrin saturation index was mainly due to increased serum iron and not to decreased TIBC.

Our findings clearly demonstrate that the observed derangement of serum iron parameters is not due to glucose intolerance but rather accompany the insulin resistance syndrome. None of our patients had any apparent abnormality in glucose disposal since all had normal glucose tolerance. The increased ferritin levels seen in overt diabetes may also be due to NASH, to decreased half-life of glycosylated ferritin ${ }^{39,40,47}$ or both.

A new syndrome named "dysmetabolic iron overload syndrome" has recently been proposed based upon the original observations of the group of Yves Deugnier ${ }^{48,49}$ and includes hyperferritinemia and increased liver iron concentration in the presence of a normal transferrin saturation. It is accompanied by hyperlipidemia, glucose intolerance and increased BMI and in many cases by non-alcoholic steatohepatitis. This important observation was followed by comments $^{50}$, an editorial ${ }^{45}$ and a perspective review ${ }^{51}$. The authors hypothesize that there is a relation between hepatic iron and steatosis and an association with insulin resistance. In some studies, mutations of the HFE gene (C282Y) associated with hemochromatosis have 
been found ${ }^{48}$, but not in others ${ }^{52,53}$. In the present study the iron parameters in the offspring of parents with DM2 were within the normal range but higher when compared to individuals without family history of type 2 diabetes.

Whatever the explanation of these findings may be, we propose that the observed abnormalities in iron metabolism in offspring of parents with DM2 represent an additional component of the well known "Metabolic Syndrome" or "Insulin Resistance Syndrome". These abnormalities are present before the abnormalities of glucose metabolism become apparent. It is thus reasonable to speculate that the abnormalities in iron metabolism in offspring of DM2 parents are the result of early liver steatosis and very mild non-alcoholic steatohepatitis. Whether the observed relative iron overload, still within the "normal" range, contributes to already existing liver insensitivity to insulin, cannot be foreseen.

\section{REFERENCES}

1. Cross CT, Halliwell BM, Borish ET, et al, 1987 Oxygen radicals and human disease. Ann Intern Med 107: 526545.

2. Giugliano D, Ceriello A, Paolisso G, 1996 Oxidative stress and diabetic vascular complications. Diabetes Care 19: 257-267.

3. Paolisso G, Gingliano D, 1996 Oxidative stress and insulin action: is there a relationship? Diabetologia 39: 35763.

4. Paolisso G, D’ Amore A, Volge C, et al, 1994 Evidence for a relationship between oxidative stress and insulin action in non-insulin-dependent (type II) diabetic patients. Metabolism 43: 1426-1429.

5. Wolff SP, 1993 Diabetes mellitus and free radicals. Free radicals, transition metals and oxidative stress in the aetiology of diabetes mellitus and complications. Br Med Bull 49: 642-652.

6. Steinberg D, Parthasarathy S, Carew TE, Kahoo JC, Witztum JL, 1989 Beyond cholesterol. Modifications of lowdensity lipoprotein that increase its atherogenicity. N Engl J Med 320: 915-924.

7. McCord JM, 1991 Is iron sufficiency a risk factor in ischemic heart disease? Circulation 83: 1112-1114.

8. Halliwell B, Gutheridge JMC, 1989 Free radicals in biology and medicine, Oxford, Clarendon press.

9. Halliwell B, Gutheridge JMC, 1990 Role of free radicals and catalytic metal ions in human disease: an overview In: Parker L, Glazer AN (eds) Methods Enzymol, San Diego, Academic Press, pp, 1-85.

10. Kaye TB, Guay AT, 1994 Increased serum ferritin levels in patients with diabetes mellitus. Mayo Clinic Proc 69: 498-499.
11. Habeos IG, Psyrogiannis A, Kyriazopoulou V, Psilopanagiotou A, Papavassiliou AG, Vagenakis AG, 2003 The role of hemochromatosis $\mathrm{C} 282 \mathrm{Y}$ and H63D mutation in the development of type 2 Diabetes mellitus in Greece. Hormones 2: 55-60.

12. Turnbull AJ, Mitckison HC, Peaston RTC, 1997 The prevalence of hereditary haemochromatosis in a diabetic population. QJM 90: 271-275.

13. Fernandez-Real JM, Ricart-Engle W, Arroyo E, et al, 1998 Serum ferritin as a component of the insulin resistance syndrome. Diabetes Care 21: 62-68.

14. Oshaug A, Bugge $\mathrm{KH}$, Bjonnes $\mathrm{CH}$, Borch-Ionsen B, Neslein IL, 1995 Associations between serum ferritin and cardiovascular risk factors in healthy young men. A crosssectional study. Eur J Clin Nutr 49: 430-438.

15. Knuts L-R, Rastas M, Haapola P, 1987 A computer program for calculation of food and nutrient intake. Third Eurofoods Meeting, Warsaw, May 24-27.

16. Matthews Dr, Hosker JP, Rudenski AS, Naylor BA, Treacher BF, Tarner RL, 1985 Homeostasis model assessment: insulin resistance and beta cell function from fasting plasma glucose and insulin concentrations in man. Diabetologia 28: 412-419.

17. Haffner SM, Kennedy E, Gonzalez C, Stern MP, Miettinen H, 1996 A prospective analysis of the HOMA model. The Mexico City Diabetes Study. Diabetes Care 19: 1138-1141.

18. Duncan MH, Singh BM, Wise PH, Carte G, AllaghbandZadeh J, 1995 A simple measure of insulin resistance. Lancet 346: 120-121.

19. Haffner SM, Stern MP, Hazuda HP, Pugh SA, Paterson SK, 1986 Hyperinsulinemia in a population at high risk for non-insulin-dependent diabetes mellitus. N Engl J Med 315: 220-224.

20. Reaven GM, 1983 Insulin resistance in noninsulin-dependent diabetes mellitus. Does it exist and can it be measured? Am J Med 74(Suppl IA): 3-17.

21. Barnett AH, Eff C, Leslie RD, Pyke DA, 1981 Diabetes in identical twins. A study of 200 pairs. Diabetologia 20: 87-93.

22. Ho LT, Chang Y, Wang JT, et al, 1990 Insulin insensitivity in offspring of parents with type 2 diabetes mellitus. Diabet Med 7: 31-34.

23. Leslie RDG, Ganesh A, Volkmann HP, Arberti KGMM, 1988 Insensitivity to insulin in offspring of non-insulindependent diabetic patients. Diab Nutr Metab 3: 235-237.

24. Haffner JM, Stern MP, Hazada HP, Mitchell BD, Patterson SK, 1988 Increased insulin concentrations in non-diabetic offspring of diabetic parents. N Engl J Med 319: 1297-1301.

25. Leslie RDG, Volkmenn HP, Poncher M, Hanning I, Orskow H, Arbet KGMM, 1986 Metabolic abnormalities in children of noninsulin dependent diabetics. Br Med J 293: 840-841.

26. Fujomoto S, Kawakani N, Ohara A, 1995 Nonenzymatic glycation of transferrin: decrease of iron-binding capacity and increase of oxygen radical production. Biol Pharm Bull 6: 396-400. 
27. Dandona P, Mussain MAM, Varghese Z, Politis D, Flyn DM, Hoffbrand A, 1983 Insulin resistance and iron overload. Ann Clin Biochem 20: 77-79.

28. Schafer A, Cheron RG, Dluhy R, Cooper B, Gleason RE, Soeldner JC, 1981 Clinical consequences of acquired transfusional iron overload in adults. N Engl J Med 304: 319-324.

29. Merkel PA, Simonson DC, Amiel SA, et al, 1988 Insulin resistance and hyperinsulinemia in patients with thalassemia major treated by hypertransfusion. N Engl J Med 318: 808-814.

30. Dmochowski K, Finegood BT, Francombe W, Tyler B, Zinman B, 1993 Factors determining glucose tolerance in patients with thalassemia major. J Clin Endocrinol Metab 77: 478-483.

31. Cavallo-Perin P, Pacini G, Cerutti F, et al, 1995 Insulin resistance and hyperinsulinemia in homozygous $\beta$-thalassemia. Metabolism 44: 281-286.

32. Niederau C, Berger M, Stremmel W, et al, 1984 Hyperinsulinemia in non-cirrhotic haemochromatosis: impaired hepatic insulin degradation? Diabetologia 26: 441-444.

33. Rovati A, Bergamaschi G, Casula S, Cerani P, Graso M, Gazzola M, 1999 The dysmetabolic iron overload syndrome is clinically and genetically distinct from HFE-related genetic hemochromatosis. Haematologica 84: 182183.

34. Kwan T, Leber B, Ahujas S, Carter R, Gerstein HC, 1998 Patients with type 2 diabetes have high frequency of the C282Y mutation of the hemochromatosis gene. Clin Invest Med 6: 251-257.

35. Wannamethee SG, Perry IJ, Shaper AG, 1996 Hematocrit and risk of NIDDM. Diabetes 45: 576-579.

36. Catalano C, Muscelli E, Quinones A, et al, 1996 Reciprocal association between insulin sensitivity and the hematocrit in man. Diabetes 45(Suppl 2): 323A.

37. Wilson PW, McGee DL, Kannel WB, 1981 Obesity, very low density lipoproteins, and glucose intolerance over fourteen years: The Framingham Study. Am J Epidemiol 114: 697-704.

38. Medalie JH, Papier CM, Goldbourt U, Herman JB, 1975 Major factors in the development of diabetes mellitus in 10,000 men. Arch Intern Med 35: 811-817.

39. Kaye TB, Guay AT, Simonson DC, 1993 Non-insulin-dependent diabetes mellitus and elevated serum ferritin levels. Diabetes Complications 7: 246-249.

40. Gallou G, Guilhem I, Poirier JY, Ruelland A, Legras B, Cloaver L, 1994 Increased serum ferritin in insulin-dependent diabetes mellitus: relation to glycemic control.
Clin Chem 40: 947-948.

41. Ford ES, Cogswell ME, 1999 Diabetes and serum ferritin concentration among U.S. adults. Diabetes Care 22: 19781983.

42. Dinneen SF, Silverberg JD, Batts KP, O' Brien PC, Ballard DJ, Rizza RA, 1994 Liver iron stores in patients with non-insulin-dependent diabetes mellitus. Mayo Clin Proc 69: 13-15.

43. Redmon JB, Pyzdrowski KI, Robertson RP, 1993 No effect of deferoxamine therapy on glucose homeostasis and insulin secretion in individuals with NIDDM and elevated serum ferritin. Diabetes 42: 544-549.

44. Ikai E, Ishizaki M, Suzuki Y, Ishida M, Noborizaka Y, Yamada Y, 1995 Association between hepatic steatosis, insulin resistance and hyperinsulinaemia as related to hypertension in alcohol consumers and obese people. J Hum Hyperten 9: 101-105.

45. MacDonald CA, Powell LW, 1999 More clues of the relationship between hepatic iron and steatosis: An association with insulin resistance? Gastrenterology 117: 12411244.

46. Tilg H, Diehl AM, 2000 Cytokines in alcoholic and nonalcoholic steatohepatitis. N Engl J Med 343: 1467-1476.

47. Mauricio D, Perez A, Riera A, Arroyo JA, de Leiva A, Gimferrer F, 1993 Serum parameters of iron metabolism in type 1 (insulin dependent) diabetes mellitus. Diab Nutr Metab 8: 315-316.

48. Moirand R, Mortaji AM, Loreal O, Pailland F, Brissot P, Deugnier Y, 1997 A new syndrome of liver iron overload with normal transferrin saturation. Lancet 349: 95-97.

49. Mendler MH, Moirand R, Turlin B, 1998 Study of HFE mutations in the "dysmetabolic iron overload syndrome". Hepatology 28: 419.

50. Ferrannini E, 2000 Insulin resistance, iron and the liver. Lancet 355: 2181-2183

51. Fernadez-Real JM, Lopez-Bermejo A, Ricart W, 2002 Cross talk between iron metabolism and Diabetes. Diabetes 51: 2348-2354.

52. Rovati A, Bergamaschi G, Casula S, Cerani P, Grasso M, Cazzola M, 1999 The dysmetabolic iron overload syndrome is clinically and genetically distinct from HFE-related GH. Haematologica 84: 182-183.

53. Orlandi E, Arbustini E, Lazzarino M, 1999 Isolated hyperferritinemia with normal transferrin saturation and dysmetabolism, in the absence of the two known mutations in the HFE gene of hereditary hemochromatosis. Haematologica 84: 181-182. 